\title{
Air or oxygen as driving gas for nebulised salbutamol
}

\author{
J G A GLEESON, S GREEN, AND J F PRICE
}

Paediatric Respiratory Laboratory, Department of Thoracic Medicine, King's College Hospital, London

SUMMARY The effects of nebulised salbutamol driven by compressed air or oxygen were compared in a randomised crossover study during 27 attacks of acute asthma. Arterial oxygen saturation fell by $2-6 \%$ during or after treatment in 10 cases: seven with compressed air, two with oxygen, and one with both driving gases. Hypoxaemia occurred in younger children and in those who fell asleep, but was not related to the level of arterial oxygen saturation before treatment or the size of the response to bronchodilator therapy. More children fell asleep with compressed air nebulisation. Arterial oxygen saturation improved and heart rates remained stable during treatment when oxygen was the driving gas. After treatment, however, arterial oxygen saturation fell and heart rates rose to values that were similar to those after treatment with compressed air. The falls in arterial oxygen saturation we observed, though comparatively small, would be clinically important on the steep part of the oxygen dissociation curve, and our results emphasise that families with home nebulisers should seek medical advice early when their children develop severe asthma. The benefits of using oxygen as the driving gas during nebulisation were transient, and in severe asthma treatment with oxygen needs to be continued after the nebulised salbutamol has been given.

There has recently been a pronounced increase in the use of nebulisers driven by air compressors to treat asthma at home. ${ }^{1}$ Nebulisers are an effective way of giving bronchodilators and prophylactic drugs to asthmatic patients who find inhalers difficult to use, and they are particularly useful in the treatment of young children. There are, however, some reasons for concern about the domiciliary use of nebulisers. Firstly, many patients with a home nebuliser have not received adequate instruction for its use. ${ }^{2}$ Secondly, some severely asthmatic patients have repeatedly used high doses of bronchodilator by nebuliser instead of seeking medical help, with fatal outcomes. ${ }^{3}$ Thirdly, home nebulisers are usually used without supplementary oxygen. Some degree of hypoxia is inevitable during an acute severe asthmatic attack and previous studies have indicated that giving high dose $\beta$ adrenergic bronchodilators by nebuliser may lead to a further decrease in oxygenation. $^{4-6}$

We therefore investigated the changes in oxygenation during and after nebulised salbutamol given with air or $100 \%$ oxygen as the driving gas in children with acute severe asthma. Oxygenation was assessed by the measurement of oxygen saturation with a pulse oximeter, a non-invasive technique that has been shown to reflect hypoxaemia accurately in infants with chronic lung disease ${ }^{j}$ and in children over 5 months of age requiring intensive care. ${ }^{8}$

\section{Patients and methods}

Any child more than 2 years old who was in hospital with an acute attack of asthma was considered for the study. Our criteria for hospital admission were a peak expiratory flow rate of less than $25 \%$ of the predicted value, or failure to respond to an adequate dose of nebulised salbutamol. Eighteen boys and eight girls aged 2 to 12 (median 7) years were studied; one girl was studied on two separate occasions three months apart, making a total of 27 studies. In addition to nebulised salbutamol, 12 were receiving intravenous aminophylline or oral theophylline, and eight were also receiving systemic corticosteroids. The duration of the attack at the time of entry was from 6 to 72 hours (median 29). Up to 18 doses of nebulised salbutamol had been given before entry but the median was two, indicating that most were studied soon after admission to hospital.

The children were given nebulised salbutamol driven by compressed air (Porta-neb 50) and $100 \%$ oxygen $(8 \mathrm{l} /$ minute $)$ in random order two to four hours apart. We established that the flow rate 
from the Porta-neb 50 was about $81 /$ minute. The children were all awake and breathing room air before each study. The dose was $0.15 \mathrm{mg} / \mathrm{kg}$ (to a maximum of $5 \mathrm{mg}$ ) diluted to $4 \mathrm{ml}$ with saline. An Inspiron minineb nebuliser pot and medium concentration oxygen mask (inspired oxygen concentration of $50-60 \%$ when driven by $100 \%$ oxygen at $8 \mathrm{l}$ /minute) were used on each occasion. Other treatment was not altered during the study period. Measurements after completing the nebulised treatment were made with the children breathing room air.

Heart, respiratory, and peak expiratory flow rates were recorded before, and 10 to 15 minutes after each treatment. Heart rate was also recorded during treatment. Arterial oxygen saturation was measured continuously using a Biox 3700 pulse oximeter for five minutes before, during, and 15 minutes after each treatment. After preparation of the skin, the finger probe was applied and a continuous digital reading of arterial oxygen saturation was displayed and recorded. The recordings were noted at 30 second intervals and mean values for the five minutes before, the last five minutes during nebulised treatment, and 5-10 and 10-15 minutes after treatment were calculated.

Five children who were receiving nebulised salbutamol four hourly at the time of entry were also studied before, during, and after nebulised saline (4 $\mathrm{ml}$ ). They were given one of four treatments, two active and two placebo, in random order at two hourly intervals with the proviso that active treatment followed placebo so that we did not interfere with the management if the acute attack. The treatments were: nebulised saline and compressed air; nebulised salbutamol and compressed air; nebulised saline and $100 \%$ oxygen, and nebulised salbutamol and $100 \%$ oxygen.

The mean arterial oxygen saturation of these children before receiving saline $(91.6 \%)$ was similar to that recorded before receiving salbutamol $(91.9 \%)$ in all 27 cases. The maximum individual fall at any time interval with nebulised saline was $1 \cdot 6 \%$. The coefficient of variation of arterial oxygen saturation (based on 11 values in each case) was calculated for eight of the 27 cases chosen at random; the mean intrasubject coefficient of variation was less than $1 \%$. We therefore considered a fall of at least $2 \%$ to be clinically important in individual patients.

Dichotomous variables were analysed by Fisher's test of exact probability or McNemar's test, where appropriate. ${ }^{9}$ Other results were analysed using Student's paired $t$ test with a check for order effects. Informed consent was obtained from all parents, and all parts of the trial, including the study using nebulised saline, were approved by the hospital ethical committee.

\section{Results}

There was no difference in the time taken to nebulise the salbutamol with the two driving gases. Respiratory rates were similar before each treatment period and did not alter significantly afterwards. The driving gas used did not make any obvious difference to the bronchodilator effect of the nebulised salbutamol when judged by changes in peak expiratory flow rate (table).

Nearly every child had a tachycardia at the outset, with mean heart rates' before treatment of 125.9 /minute (air) and $122.6 /$ minute (oxygen), $\mathrm{p}>0 \cdot 1$. During treatment with compressed air, mean heart rate increased $(\mathrm{p}<0.001)$ and this increase was sustained after treatment $(\mathrm{p}<0 \cdot 01)$. No such increase occurred during treatment with oxygen $(p>0.05)$, but there was an increase in mean heart rate after treatment $(\mathrm{p}<0 \cdot 01)$. There was no order effect (fig 1).

The figures for arterial oxygen saturation were similar before each treatment; before treatment with air the mean was $92.0 \%$ (range $86.9-95.5 \%$ ) and before treatment with oxygen the mean was $91.9 \%$ (range $88 \cdot 1-94 \cdot 9 \%$ ). There were no significant changes in mean arterial oxygen saturation for the group as a whole during or after treatment with compressed air. When the children were given

Table Changes in respiratory $(n=27)$ and peak expiratory flow rates and nebulisation times when treatment was driven by compressed air or by $100 \%$ oxygen

\begin{tabular}{|c|c|c|c|c|}
\hline & \multicolumn{2}{|l|}{ Air } & \multicolumn{2}{|l|}{ Oxygen } \\
\hline & $\begin{array}{l}\text { Before } \\
\text { treatment }\end{array}$ & $\begin{array}{l}\text { After } \\
\text { treatment }\end{array}$ & $\begin{array}{l}\text { Before } \\
\text { treatment }\end{array}$ & $\begin{array}{l}\text { After } \\
\text { treatment }\end{array}$ \\
\hline Mean $(\mathrm{SD})$ respiratory rate & $31 \cdot 8(11 \cdot 2)$ & $32 \cdot 7(10 \cdot 3)$ & $32 \cdot 3(11 \cdot 7)$ & $31 \cdot 2(9 \cdot 1)$ \\
\hline Mean (SD) peak expiratory flow rate (\% of predicted)* & $57 \cdot 2(29 \cdot 2)$ & $67 \cdot 3(28 \cdot 1)$ & $58 \cdot 0(30 \cdot 3)$ & $70 \cdot 0(30 \cdot 0)$ \\
\hline Mean (SD) time on nebuliser (minutes) & \multicolumn{2}{|c|}{$9.9(2.2)$} & \multicolumn{2}{|c|}{$9.7(2.3)$} \\
\hline
\end{tabular}

${ }^{*}$ Seven of 19 patients on air and 10 of 20 on oxygen had a rise of $>10 \%$. 
nebulised salbutamol driven by oxygen, there was a rise in mean arterial oxygen saturation which lasted until the end of the treatment. During the period immediately after treatement, the mean arterial oxygen saturation fell, and stabilisation took up to five minutes. The mean arterial oxygen saturation 5-10, and 10-15, minutes after treatment using oxygen did not differ either from the baseline value or from the mean arterial oxygen saturation after treatment using compressed air (fig 2).

Arterial oxygen saturation fell by at least $2 \%$ from the value before treatment in 10 children: seven when compressed air was used, two when oxygen was used, and one with both driving gases. During treatment using compressed air, four children had falls of $2-3 \cdot 5 \%$. In two of these and in a further four children, arterial oxygen saturation was at least $2 \%$ below baseline values 5-15 minutes after the end of the treatment. This fall was greater than $4 \%$ in three cases, the greatest being $6.1 \%$ to an arterial oxygen saturation of $85.4 \%$. In three cases arterial oxygen saturation fell by more than $2 \%$ after nebulised salbutamol driven by $100 \%$ oxygen (one had also had a pronounced fall in arterial oxygen saturation when compressed air was used); one child had a drop in arterial oxygen saturation of over $4 \%$.

The 10 children who developed clinically important hypoxaemia did not differ from the others in either pulse or respiratory rate, or peak expiratory

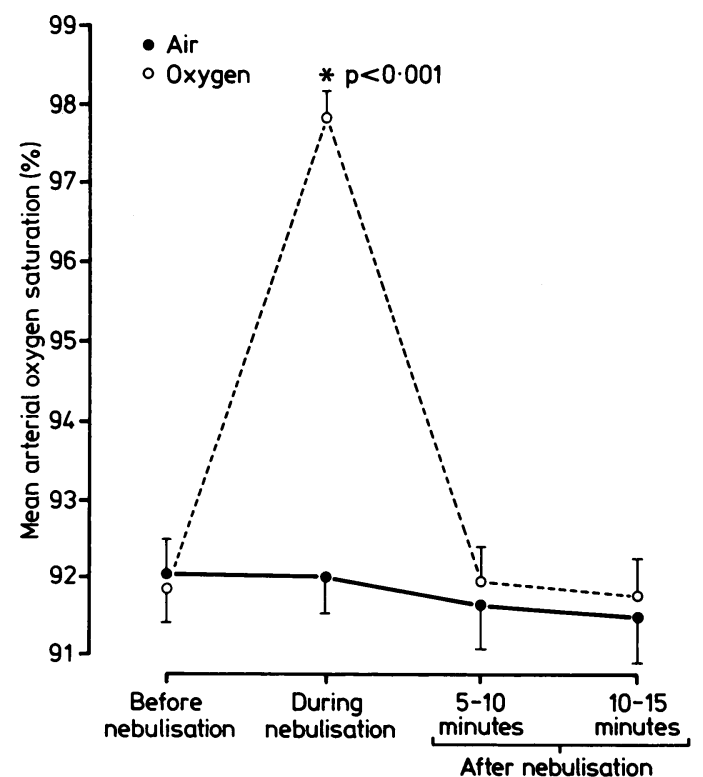

Fig 1 Mean arterial oxygen saturation in 27 cases before, during, and after nebulised salbutamol driven by compressed air or $100 \%$ oxygen. Bars indicate $1 S E$.

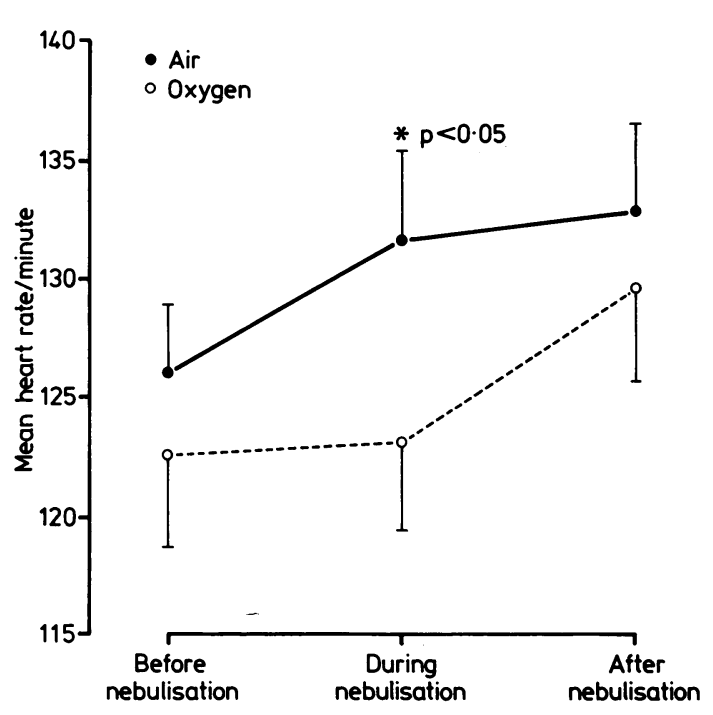

Fig 2 Mean heart rate in 27 cases before, during, and after nebulised salbutamol driven by compressed air or $100 \%$ oxygen. Bars indicate $1 S E$.

flow rate, or arterial oxygen saturation, or other medication, before treatment. Eight of them (including the four whose arterial oxygen saturation fell by more than $4 \%$ ) were under the age of 7 years, and five fell asleep during or after treatment. Children fell asleep more often when compressed air was used (nine out of 27) than when oxygen was the driving gas (two out of 27); $<<0.05$, McNemar's test.

\section{Discussion}

Hypoxaemia after treatment with bronchodilators probably reflects a comparatively greater increase in pulmonary perfusion than in ventilation-that is an increase in ventilatory perfusion mismatch. This increase in perfusion may be due to a $\beta$-2-adrenergic pulmonary vasodilation effect or a $\beta$-1-adrenergic effect that increases cardiac output, or both. ${ }^{10}$ The frequency and degree of hypoxaemia that we observed was less than that described in previous studies of salbutamol inhalation in wheezing children. The mean arterial oxygen saturation did not decrease in our group of patients, and arterial oxygen saturation decreased by at least $2 \%$ in only 11 of 54 studies. In one study a fall in arterial oxygen saturation of more than $5 \%$ in nine of 18 asthmatic children aged 2-15 years was reported. ${ }^{4}$ In this study, arterial oxygen saturation before treatment was higher and heart rates were lower than in our patients, suggesting that the airways obstruction 
may not have been as severe. They recorded arterial oxygen saturation at fixed time points so their results would not allow for brief fluctuations in saturation. Also, no mention was made of the quality of the pulse wave forms obtained, and (as has been pointed out recently) artifactual falls in arterial oxygen saturation can result from inadequate waveforms. $^{8}$ The pulse oximeter we used (Biox 3700 ) displays the pulse wave patterns and quantifies the strength of the signal so that values recorded during suboptimal conditions can be disregarded.

The one study of oxygenation in wheezy infants after nebulised salbutamol showed a significant deterioration in the five babies investigated. ${ }^{6}$ It was suggested that abnormalities in ventilation perfusion and therefore hypoxaemia might be more likely to occur in infants because they frequently do not dilate their bronchi in response to salbutamol and, indeed, obstruction to the airways may actually increase. ${ }^{11}$ In our study the children who showed the largest falls in oxygen saturation were among the youngest, but there was no association between fall in arterial oxygen saturation and a poor response to nebulised salbutamol.

Giving nebulised salbutamol with oxygen as the driving gas had two potential benefits. Firstly (as one might expect), hypoxaemia did not occur during treatment. Five to 15 minutes after completion of treatment, however, arterial oxygen saturation was no different from that when compressed air was used, and pronounced hypoxaemia still occurred in a few patients. Secondly, the children were less likely to fall asleep when given oxygen with nebulised salbutamol. Drowsiness was noted as an occasional unwanted effect in a survey of the use of home nebulisers, ${ }^{2}$ and in our previous study five of 19 children with acute asthma fell asleep after being given nebulised salbutamol driven by compressed air. ${ }^{5}$ These five children, and four of the nine children who fell asleep after nebulised treatment using compressed air in our present study, showed a fall in oxygenation. Sleep in chronic adult asthmatics is associated with hypoventilation and a decrease in arterial oxygen saturation. ${ }^{12}$ Respiratory rates did not alter in our patients, but we did not measure tidal volume so hypoventilation could be at least partly responsible for the hypoxaemia. In support of this view, the larger number of patients who became hypoxaemic after nebulised salbutamol driven by compressed air can be explained by their sleep state; in those who remained awake the frequency of hypoxaemia was similar after both driving gases. It is not at all clear why treatment using compressed air should be more likely to induce sleep, but it is probably not the noise of the compressor because compressors were not used in our earlier study.
The increase in heart rate that occurred during treatment with nebulised salbutamol driven by compressed air did not occur during treatment with nebulised salbutamol driven by oxygen. There was a slight increase in heart rate during treatment with nebulised saline and there was no difference when the nebulised saline was driven by air or oxygen. It is difficult to explain this possible inhibition of the $\beta 1$ effect of salbutamol by oxygen, but heart rates rose when oxygen was discontinued.

The recent New Zealand Asthma Mortality Study concluded that in all cases where home nebulisers driven by compressed air were used during the final attack the probability that inhalation of $\beta$ sympathomimetics by nebuliser contributed to death was lower than the probability that death would have occurred without treatment'. ${ }^{3}$ It is reassuring that in most of the children we studied nebulised salbutamol driven by compressed air was not associated with hypoxaemia, and when arterial oxygen saturation did fall the changes were comparatively small. On the other hand, hypoxaemia was unpredicatable and although a fall of $2-6 \%$ is probably not clinically important when arterial oxygen saturation is above $90 \%$, it would be extremely important if the arterial oxygen saturation before treatment with the nebuliser was less than $85 \%$ and on the steep part of the oxygen dissociation curve.

Our observations emphasise the importance of explaining to parents of children with nebulisers at home that when the child has an acute attack of asthma they shoiuld not persist with unsupervised use of the nebuliser. We recommend that they seek medical advice if there is no improvement after one dose of nebulised salbutamol or if it is needed more often than four hourly. Using oxygen as the driving gas conferred only transient benefit, and oxygen needs to be given continuously to children who are extremely hypoxaemic during a severe acute asthmatic attack.

J Gleeson is supported by a research grant from the Children Nationwide Medical Research Fund. We thank Miss Kerry Jones for typing the manuscript.

\footnotetext{
References

1 Editorial. Nebuliser epidemic. Lancet 1984;ii:789-90.

2 Laroche CM, Harmes AVK, Newton RCF, Britton ME. Domiciliary nebulisers in asthma: a district survey. $\mathrm{Br}$ Med $\mathrm{J}$ 1985;290:1611-3.

${ }^{3}$ Sears MR, Rea HH, Fenwick J, et al. 75 Deaths in asthmatics prescribed home nebulisers. Br Med J 1987;294:477-80.

4 Tal A, Pasterkamp H, Leahy F. Arterial oxygen desaturation following salbutamol inhalation in acute asthma. Chest 1984;86: 868-9.

5 Loftus BG, Price JF. Home nebulisers. Lancet 1985;i:395.

6 Prendiville A, Rose A, Maxwell DL, Silverman M. Hypoxaemia
} 


\section{Gleeson, Green, and Price}

in wheezy infants after bronchodilator treatment. Arch Dis Child 1987:62:997-1000.

7 Solimano AJ, Smyth JA, Mann TK, Albersheim SG, Lockitch G. Pulse oximetry advantages in infants with bronchopulmonary dysplasia. Pediatrics 1986;78:844-9.

' Southall DP, Bignall S, Stebbens VA, Alexander JR, Rivers PRA, Lissauer T. Pulse oximeter and transcutaneous arterial oxygen measurements in neonatal and paediatric intensive care. Arch Dis Child 1987;62:882-8.

${ }^{y}$ Everitt BS. The analysis of contingency tables. London: Chapman and Hall, 1977.

10 Harris L. Comparison of the effect on blood gases, ventilation and perfusion of isoproterenol-phenylephrine and salbutamol aerosols in chronic bronchitis with asthma. $J$ Allergy Clin Immunol 1972;49:63-71.

11 Prendiville A, Green S, Silverman M. Paradoxical response to nebulised salbutamol in wheezy infants, assessed by partial expiratory flow volume curves. Thorax 1987;42:86-91.

12 Catterall JR, Douglas NJ, Calverley PMA, et al. Irregular breathing and hypoxaemia during sleep in chronic stable asthma. Lancet 1982;i:301-4.

Correspondence and requests for reprints to Dr JF Price, Department of Child Health, King's College Hospital, London SE5 8RX.

Accepted 11 January 1988 